\title{
Telephone assistance for smoking cessation: one year cost effectiveness estimations
}

\author{
A L McAlister, V Rabius, A Geiger, T J Glynn, P Huang, R Todd
}

Tobacco Control 2004;13:85-86. doi: 10.1136/tc.2003.004515

A randomised trial evaluated the American Cancer Society's telephone counselling service to assist smoking cessation. Counselling nearly doubles a smokers' odds of quitting and maintaining cessation for one year. The estimated cost for each case of maintained smoking cessation attributable to counselling availability is approximately $\$ 1300$.

$\mathrm{T}$ he provision of support and assistance for smoking cessation may provide great benefits at a relatively modest cost. ${ }^{1}$ But cost benefit and cost effectiveness estimations often lack precise data on the incremental effects on cessation that will result from the provision of specific services. ${ }^{2}$ Randomised trials are required for precise cost effectiveness calculations. ${ }^{3}{ }^{4}$ Telephone counselling services can be delivered conveniently and they have been shown to increase quitting success and maintenance rates. ${ }^{5-8}$ This report summarises one year follow up results and cost effectiveness estimations from a randomised trial designed to evaluate a new telephone counselling service established by the American Cancer Society in the summer of 2000.

\section{PARTICIPANTS AND METHOD}

Smokers participating in this study were recruited by mass media promotion carried out by the Texas Department of Health in Houston and east Texas. Between 26 June and 15 November 2000, 3518 called and 1014 (29\%) met the recruitment criterion by agreeing to make a quit attempt within two weeks. Among this group 463 were randomised to receive mailed self help booklets and 551 were randomised to receive booklets and to be eligible for telephone counselling (numbers are unequal because of a failure of the randomisation programme during one week of the enrolment period). All study participants were mailed three American Cancer Society booklets that provide standard advice designed to help smokers identify their individual needs and learn appropriate self help techniques for moving through stages of cessation. The booklets also contain guidelines for assessing addiction and selecting appropriate medications (for example, nicotine replacement therapy and/or bupropion) to aid quitting.

The smokers randomised to receive telephone assistance were sent booklets and provided tailored counselling based on recognised guidelines, ${ }^{9}$ the stages of change identified by Prochaska et al, ${ }^{10}$ principles of social cognitive theory, ${ }^{11}$ and motivational interviewing techniques. ${ }^{12}$ Five sessions were available and clients could "recycle" at least once if they failed to quit or to maintain cessation. The first session occurs immediately after enrolment or at the earliest convenient date. The second session is held approximately two days before the selected quit date, and a third session is held on the day after the quit date. The fourth session is five to seven days later and a fifth and final session is held approximately one week after that. Callers were not charged for service, but the approximate cost per client ranged from $\$ 30$ for those who did not receive more than one session to $\$ 100$ for those who received the full counselling service. These costs estimates include staffing, fulfilment, telephone, evaluation, overhead, and infrastructure costs. The cost of taking calls and mailing self help books to smokers who want to quit, which was the current practice at the call centre, was approximately $\$ 15$ for each smoker served.

The study group consisted of $37 \%$ men (mean age 41.7 years) and 63\% women (mean age 41.9) and is 71\% "Anglo" or "white" and 20\% African American, with approximately $5 \%$ Hispanic and 4\% "other" ethnic group participation. The average daily smoking rate at baseline was 23.0 in the counselling group and 23.1 in the self help group. The mean number of previous quit attempts was 6.6 in the counselling group and 7.0 in the self help group. There were no significant differences in the characteristics of smokers in the two experimental groups or among those who did or did not enter the study.

All participants completed a baseline interview and an effort was made (with up to 20 call attempts if needed) to interview them all again 12 months after the presumed quit date (two weeks after enrolment in the study). Cases who reported that they were abstinent at the time of the call and who experienced no more than five single-day slips (brief relapses) were considered to have maintained cessation. Of the 551 callers assigned to receive counselling, 275 (50\%) were successfully interviewed in the one year follow up. Among the 463 callers assigned to receive booklets but no counselling, 204 (45\%) were followed accordingly. The causes of loss to follow up were refusal (19\%), changes to unlisted or disconnected numbers (55\%), and failures to answer (36\%). To verify self reports, 19 study participants in the Houston area from both study groups were asked to provide saliva samples for nicotine testing and to confirm non-smoking status at a face-to-face interview. Among this group, 15 attended the interviews and all of them were found to be free of nicotine: 9 (of 12) in the counselling group and 6 (of 7) in the self-help group.

\section{RESULTS}

If the quit rate calculation includes only those who were reached for follow up interviews and makes no assumptions about those who were not reached, the estimated quit rates are $20.7 \%$ (57/275) in the counselling group and $13.2 \%$ (27/ 204) in the self help only group, a net increment of approximately $8 \%\left(\chi^{2}\right.$ test, $\left.\mathrm{p}<0.01\right)$. The most conservative method for calculating effects assumes that cases lost to follow up did not stop smoking. Based on this criterion the maintained cessation rate (no more than five single-day slips in a three month interval) is $10.3 \%(57 / 551)$ in the group offered counselling and $5.8 \%(27 / 463)$ in the group receiving booklets only. The net increment is $4.5 \%$ ( $\chi^{2}$ test, $\left.p<0.01\right)$. 


\section{What this paper adds}

Telephone counselling has been shown to help smokers quit, but cost effectiveness has not been reported. This paper presents one year cost effectiveness estimations from the American Cancer Society's telephone counselling service. It shows that promotion of a telephone counselling service to assist smoking cessation can yield responses from many smokers who are ready to quit, and that a large proportion of callers will use counselling if it is offered.

The cost of each case of smoking cessation attributable specifically to the availability of the telephone counselling service can be estimated by dividing the average cost per client by the incremental effect on cessation rates. Many callers who were eligible for counselling did not complete more than one session (58\%) and the approximate individual cost among this group was $\$ 30$. For those who received two or more sessions (42\%) the approximate cost was $\$ 100$. Thus the average cost per client eligible for counselling was approximately $\$ 60$, excluding recruitment costs for promotion of the service. The estimated incremental effect on cessation rates, using the most conservative analysis in which non-respondents are assumed not to have quit, was $4.5 \%$. Dividing the added cost by the incremental effect, the direct cost for each case of one year cessation attributable to counselling availability is approximately $\$ 1300$.

\section{DISCUSSION}

This study shows that promotion of a telephone counselling service to assist smoking cessation can yield responses from many smokers who are ready to quit, and that a large proportion of callers will use counselling if it is offered. Access to counselling almost doubled maintained quit rates over one year. This compares well with effects found in previous studies. ${ }^{13}{ }^{14}$ While further research and longer term follow up will continue to refine and evaluate the service, these promising results in Texas have led the American Cancer Society to expand availability to other states.

\section{ACKNOWLEDGEMENTS}

The authors wish to acknowledge the contributions of Michael Telch, $\mathrm{PhD}$, Kimberly G Hollister, Susan Stormer, PhD, and the telephone counselling team: Shelley MacAllister (Team Supervisor), Efrain Davila, Amy Donchey, Evan Odensky, Joanne Pike, Kathy Ropers, Kelly Todd, and Kenya Varnado.
Funding for this work was provided by the Texas Department of Health.

\section{Authors' affiliations}

A L McAlister, Center for Health Promotion and Prevention Research, School of Public Health, University of Texas Health Science Center at Houston, Houston, Texas, USA

V Rabius, A Geiger, T J Glynn, R Todd, American Cancer Society, Atlanta, Georgia, USA

P Huang, Bureau of Chronic Disease and Tobacco Prevention, Texas Department of Health, Austin, Texas, USA

Correspondence to: A McAlister, PhD, Center for Health Promotion and Prevention Research, School of Public Health, The University of Texas Health Science Center at Houston, 7000 Fannin, Suite 2550, Houston, TX 77030, USA; amcalister@sph.uth.tmc.edu

Received 13 May 2003

Accepted 1 October 2003

\section{REFERENCES}

1 Cromwell J, Bartosch WJ, Fiore MC, et al. Cost-effectiveness of the clinical practice recommendations in the AHCPR guideline for smoking cessation. JAMA 1997;278:1759-66.

2 Curry SJ, Grothaus LC, MCAffee T, et al. Use and cost effectiveness of smoking cessation services under four insurance plans in a health maintenance organization. N Engl J Med 1998;339:673-679.

3 Croghan IT, Offord KP, Evans RW, et al. Cost-effectiveness of treating nicotine dependence: the Mayo Clinic experience. Mayo Clin Proc 1997;72:917-24.

4 Oster G, Huse DM, Delea TE, et al. Cost-effectiveness of nicotine gum as an adjunct to physician's advice against cigarette smoking. JAMA 1986;256:1315-8

5 Orleans CT, Schoenbach VJ, Wagner EH, et al. Self-help quit smoking interventions: Effects of self-help materials, social support instructions and telephone counseling. J Consult Clin Psychol 1991;59:439-48.

6 Lando HE, Hellerstedt WL, Pirie PL, et al. Brief supportive telephone outreach as a recruitment and intervention strategy for smoking cessation. Am J Public Health 1992;82:41-6.

7 Zhu S-H, Melcer T, Sun J, et al. Smoking cessation with and without assistance. Am J Prev Med 2000;18:305-11.

8 US Department of Health and Human Services. Reducing tobacco use: a report of the Surgeon General. US Department of Health and Human Services, 2000.

9 United States Department of Health and Human Services. Clinical Practice Guideline: treating tobacco use and dependence. United States Department of Health and Human Services, 2000.

10 Prochaska JO, DiClemente CC, Norcross JC. In search of how people change: Applications to addictive behaviors. Am Psychol 1992;47:1 102-14.

11 Bandura A. Social foundations of thought and action: a social cognitive theory. Englewood Cliffs. New Jersey: Prentice-Hall Inc, 1986.

12 Miller WR, Rollnick S. Motivational interviewing: preparing people to change addictive behavior. New York: The Guilford Press, 1991.

13 Zhu S-H, Stretch V, Balbanis M, et al. Telephone counseling for smoking cessation: effects of single-session and multiple-session interventions. J Consult Clin Psychol 1996;64:202-11.

14 Borland R, Segan CJ, Livingston PM, et al. The effectiveness of callback counselling for smoking cessation: a randomized trial. Addiction $2001 ; 96: 881-9$. 